\title{
Shoreline recovery from storms on the east coast of Southern Africa
}

\author{
S. Corbella ${ }^{1,2}$ and D. D. Stretch ${ }^{1}$ \\ ${ }^{1}$ Centre for Research in Environmental, Coastal \& Hydrological Engineering, School of Civil Engineering, University of \\ KwaZulu-Natal, Durban, 4041, South Africa \\ ${ }^{2}$ eThekwini Municipality, Coastal Engineering \& Drainage Unit, P.O. Box 680, Durban, South Africa
}

Correspondence to: S. Corbella (corbellas@ durban.gov.za)

Received: 25 July 2011 - Revised: 8 November 2011 - Accepted: 9 November 2011 - Published: 2 January 2012

\begin{abstract}
Episodic extreme waves due to sea storms can cause severe coastal erosion. The recovery times of such events are important for the analysis of risk and coastal vulnerability. The recovery period of a storm damaged coastline represents a time when the coastline is most vulnerable and nearby infrastructure is at the greatest risk. We propose that identification of the beach recovery period can be used as a coastal management tool when determining beach usage. As a case study, we analyse $37 \mathrm{yr}$ of beach profile data on the east coast of South Africa. Considering beach length and cross-sectional area, we establish a global recovery period and rate and identify the physical characteristics of the coastlines that either accelerate or retard recovery. The beaches in the case study were found to take an average of two years to recover at a rate of approximately $90 \mathrm{~m}^{3} \mathrm{~m}^{-1} \mathrm{yr}^{-1}$. Beach profiles with vegetated dunes recovered faster than urbanized beaches. Perpendicular beach structures have both positive and negative effects on beach recovery. Coastlines with rock outcrops in the surf zone tend to recover slowly and longterm sediment loss was identified in cases where storm damaged beaches have not recovered to pre-erosion levels.
\end{abstract}

\section{Introduction}

Erosion of coastlines is an age old problem faced by coastal communities. Durgappa (2008) claimed that sandy shores make up approximately $20 \%$ of the world's coastline and of this more than $60 \%$ has experienced severe erosion over the past few decades. Apart from anthropogenic effects and sea level rise contributing to erosion, various elements of wave climate cause erosion. It is easy to perceive that a large wave height as well as this wave height being sustained for a long duration can produce erosion (e.g,. Kriebel and Dean, 1993; Callaghan et al., 2009). An increase in wave period has also been shown to increase erosion (van Gent et al., 2008; van Thiel, 2008). The inter-arrival time of storm events does not necessarily influence the quantity of sediment removed during a given event. This is because a new equilibrium profile is established during the initial storm and a subsequent storm of less or equal wave power will not erode the profile any more. However, the new equilibrium profile does effect the vulnerability of coastal developments. A storm event erodes a beach and reduces the natural buffer between the ocean and the hinterland. It is at this stage that an urbanized coastline is at risk of sustaining severe damage from a subsequent, possibly less extreme, storm event before it has fully recovered to its pre-storm level (Forbes et al., 2004).

During these periods of heightened vulnerability, a global estimate of the recovery time of storm damaged beaches is valuable to coastal managers for estimating the probability of storm events falling within the recovery period. The analysis of inter-arrival times in sea storm applications has been used in risk modelling by De Michele et al. (2007). Research regarding shoreline erosion is plentiful (recent examples include van Rijn, 2009; Callaghan et al., 2008; Miller and Dean, 2004), but there is much less on the recovery of beaches to their pre-storm positions (Morton et al., 1994). Coastal management is fraught with uncertainty (Otter and Capobianco, 2000) and social conflicts over the use of coastal resources (Cooper et al., 2008). Information on beach recovery periods enables coastal managers to make more informed decisions in planning for coastal hazards and appropriate use of coastal resources. Choowong et al. (2009) found that the Bang Niang to Khuk Khak coastline of Phang-nga took two years to recover after the 2004 Indian Ocean tsunami, while Liew et al. (2010) found that the Khao Lak coast also took approximately two years to recover. Morton et al. (1995) found that the Texan coastline requires 4 to $5 \mathrm{yr}$ for volumetric and geomorphic beach recovery from moderate storm events. The consideration of 
geomorphic beach recoveries is thought to make the results of Morton et al. (1995) longer than Choowong et al. (2009) and Liew et al. (2010) who only considered volumetric recovery. A beach's recovery is dependent on its sediment supply and the severity of the erosion event in question (Houser et al., 2008). The sediment that is transported offshore by undertow during an erosion event (Gracia et al., 2002) is slowly worked back onshore under calm conditions (Shepard, 1950). Depending on the severity of the event, the sediment may be carried sufficiently far offshore to prolong or even prevent its return (Forbes et al., 2004). Location is important for recovery, not only because of wave shoaling and refraction effects, but also because of the location of rivers which have been estimated to supply about $80 \%$ of global beach sediments (GESAMP, 1994).

The KwaZulu-Natal coastline on the east coast of South Africa experienced its largest recorded wave event in March 2007. The event caused severe coastal damage. Peoples' perceptions about the recovery of the beaches vary with many of them saying the coastline has fully recovered while others say it has not. This paper will show how both perceptions may be correct as well as providing an average recovery period.

This paper reports observations of recovery times and recovery rates for beach erosion from storm events on the east coast of South Africa. It also explores the implications of cases where shorelines do not recover to their pre-storm level prior to subsequent storm events.

The methods used for the case study are described in Sect. 2. We then present the recovery results of all the identified major erosion events in Sect. 3 before focusing on the largest erosion event on record (March 2007). Finally we summarise the conclusions of the study.

\section{Methods}

\subsection{Case study site}

Durban is a coastal city on the east coast of South Africa (Fig. 1). Durban's local authority, the eThekwini Municipality, is responsible for almost $100 \mathrm{~km}$ of predominantly sandy coastline. Durban's struggle to balance the establishment of a port against beach erosion has resulted in a substantial beach monitoring and sand bypass scheme (Barnett, 1999). Beach profiles have been recorded since 1973, but were restricted to the central beaches (Fig. 2c). Numerous profiles have since been included in the monitoring programme, some as recent as 2007. All the profiles are measured at least every 3 months. Since not all the profiles had the same record length, it was decided to analyse a period that contained most of the profiles which conveniently coincided with the first records from wave recording buoys, 1992 to 2010 . The profile lengths and volumes were also analysed from 1973 to
2010 for those that were available. All profile locations are shown in Figs. 1 and 2.

The profiles are recorded relative to chart datum (CD) which is the height of the lowest astronomical tide. Beach profiles are rarely measured below $1 \mathrm{~m} \mathrm{CD}$ and, therefore, all volumes were calculated above the $1 \mathrm{~m} \mathrm{CD}$ contour which is approximately equal to mean sea level (Fig. 4). Based on the concept of an equilibrium profile, an area well below CD would be inappropriate as the sediment eroded from above $\mathrm{CD}$ would be deposited below $\mathrm{CD}$, but above the closure depth and no net profile erosion would be measured.

The average wave conditions on the east coast of South Africa are a significant wave height of $1.65 \mathrm{~m}$ with an average direction of 121 degrees. These conditions produce a net littoral drift towards the north of between $300000 \mathrm{~m}^{3}$ and $500000 \mathrm{~m}^{3}$ (Schoonees, 2000; CSIR, 2008).

\subsection{Recovery}

The recovery of both profile volumes and profile lengths were considered. The pre-erosion values were used to establish an average level before the event. The profile was only considered to have recovered once it had passed the average level on at least three consecutive recordings. The difference between the recovery date and the event date defines the recovery period while the recovery rate is defined as the volume recovered per unit time during the recovery period. Whence

$$
\begin{aligned}
\text { recovery period } & =D_{\text {recovery }}-D_{\text {event }} \\
\text { recovery rate } & =\frac{V_{\text {recovered }}}{\text { recovery period }}
\end{aligned}
$$

where $D_{\text {event }}$ denotes the date of the erosion event, $D_{\text {recovery }}$ the recovery date and $V_{\text {recovered }}$ the volume recovered. The definitions of recovery period and recovery rate are illustrated in Fig. 3. On occasion, the profiles did not recover to the average - these were noted along with the value that they were able to recover to, and an estimate of the recovery rate. This recovery rate was then used to establish what the recovery period would have been at that estimated rate. Volumes were determined from the profile cross-sectional areas and the distances between the profiles by the end areas method. The profiles are measured at different intervals ranging from $112 \mathrm{~m}$ to $1809 \mathrm{~m}$. The profiles with large gaps may not be representative of the actual beach volume changes and so the areas (or volume per metre) are the preferred analysis quantity. The volume recovery periods and rates are ultimately the same measure as those of the volume per metre. The volume results are, therefore, not presented as they can be estimated by multiplying the length of coastline by the average profile volume per metre. 


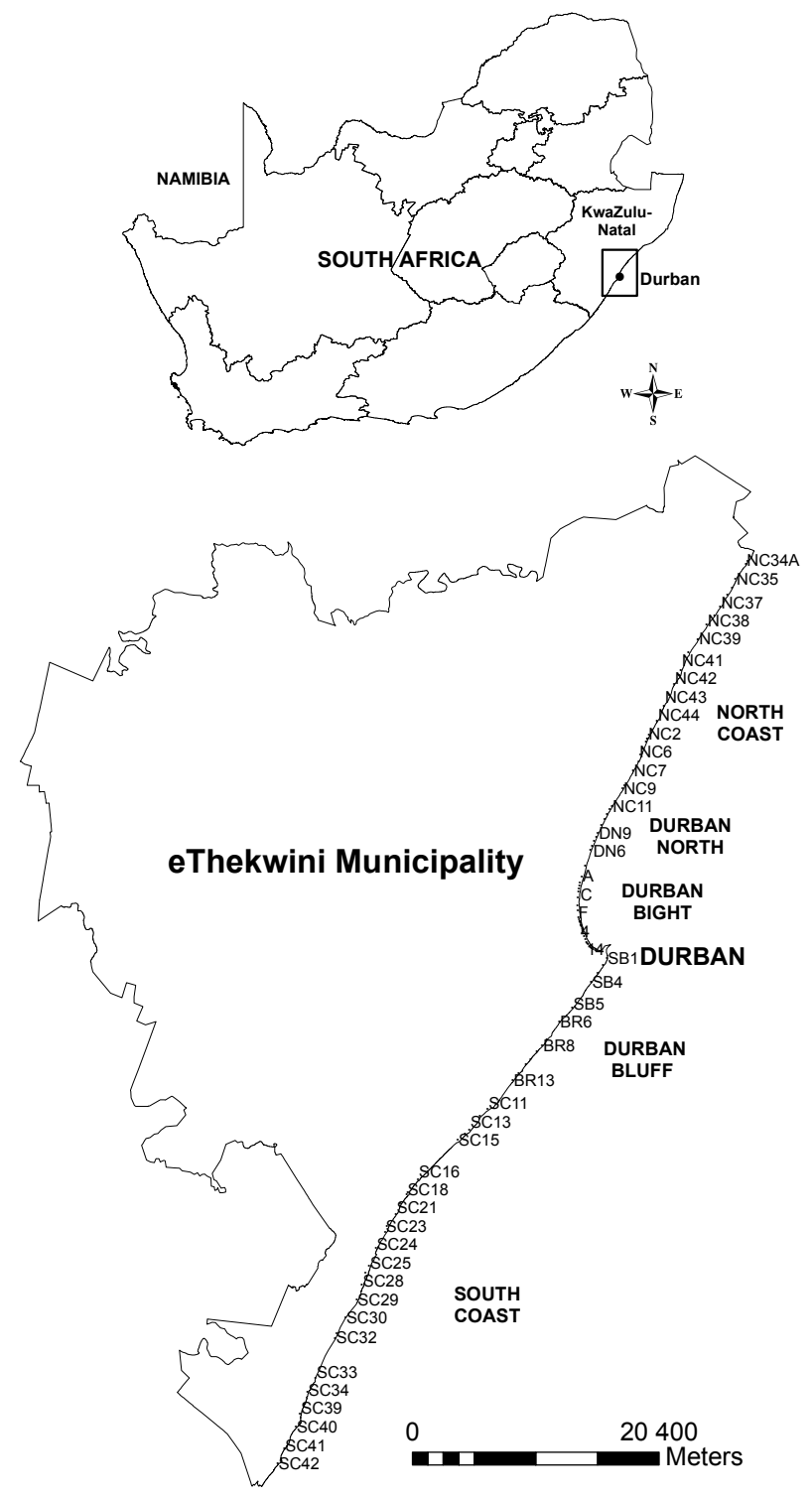

Fig. 1. A map of South Africa showing KwaZulu-Natal and Durban and a map of the eThekwini Municipality showing the beach profiles.

\subsubsection{Volume recovery}

The profile volume per unit length (Fig. 4) was defined as the profile area above $1 \mathrm{~m} \mathrm{CD}$. Beach profile volumes were analysed chronologically to determine erosion events.

Since the recovery period depends on the location of the profile and the severity of the event, these dependencies had to be considered when estimating a global beach recovery period. Ensemble averaged recovery periods and rates were estimated using three different groupings of data, namely:

- Location grouped volume recovery: The profiles were grouped together into blocks based on location, espe- cially with regards to rivers. The groups created were: A - 23, BR6 - BR10, DN6 - DN13, NC3 - NC10, NC34 - NC40, NC40 - NC44, SB1 - SB5, SC11 SC15, SC16 - SC24, SC25 - SC32, SC33 - SC44. Ensemble averaged recovery periods and rates were then calculated for each location group.

- Event grouped volume recovery: The profiles were grouped into erosion events and then an average recovery period and rate were determined per event.

- Individual profile volume recovery: An average recovery period and rate was established for each profile by considering all the erosion events that the profile experienced.

A global recovery period and rate was calculated from the average of all three groupings.

Note that in some cases specific profiles could not be included in the above analysis because they were inconsistent in their responses and no recovery period or rate could be established. This is probably due to local sheltering effects.

\subsubsection{Length recovery}

Location group A - 23 was unique as it had the longest data record as well as being directly affected by the sand bypass scheme. Certain profiles within A - 23 have been recorded since 1973. The Durban Bight has historically been a major concern to the eThekwini Municipality as a result of the port's dredging activities. Profiles $(1-23)$ were not useful in terms of recovery periods as they are dependent on the sand bypass volumes. Only profiles A-G were considered as they are furthest away from the sand pumping influence.

The lengths were not considered with the volumes as they are not truly representative of recoveries. This is because a change in length does not necessarily mean a net change in the profile sediment amount and may simply describe an evolution in profile shape.

The extensive record of lengths were analysed differently to that of the volumes. The profile lengths at the $2 \mathrm{~m} \mathrm{CD}$ and the $4 \mathrm{~m} \mathrm{CD}$ contour (see Fig. 4) were analysed as they represent approximately the lower and upper bounds of the swash zone, respectively. A recovery period was defined as recovery to the average length instead of the pre-event average as in the case of the volume calculation.

The results in location group A - G were ensemble averaged by grouping according to events.

\section{Results}

Major events were defined as the profiles' lowest levels and did not necessarily coincide with the responsible storm event. The periods around 1998, 2004 and 2007 were identified as major erosion events between 1992 and 2009. 


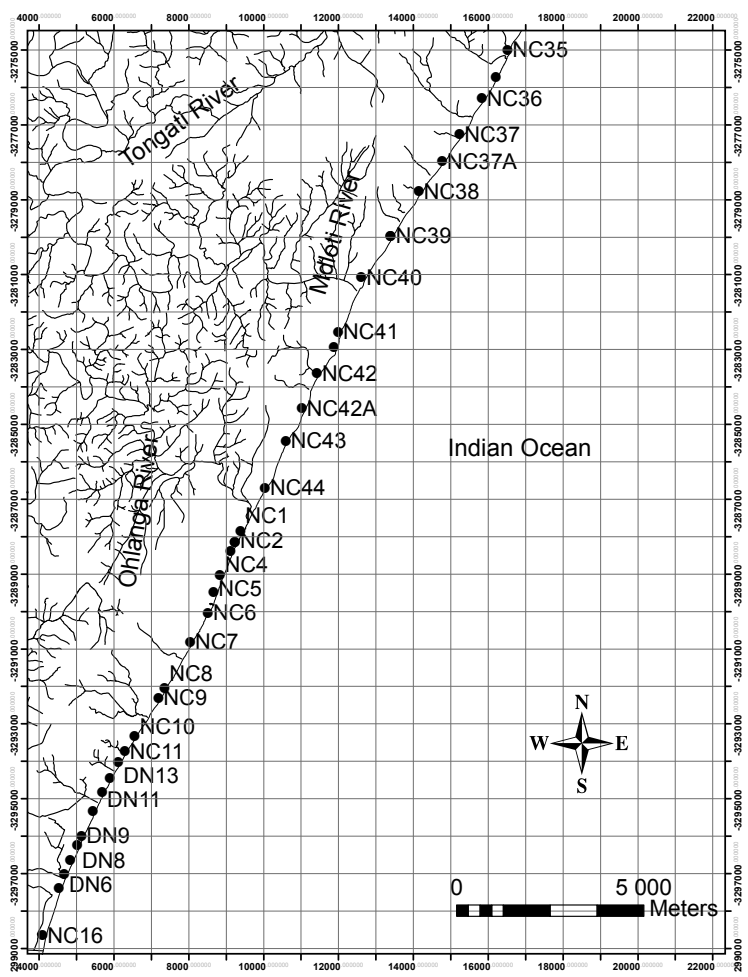

(a)

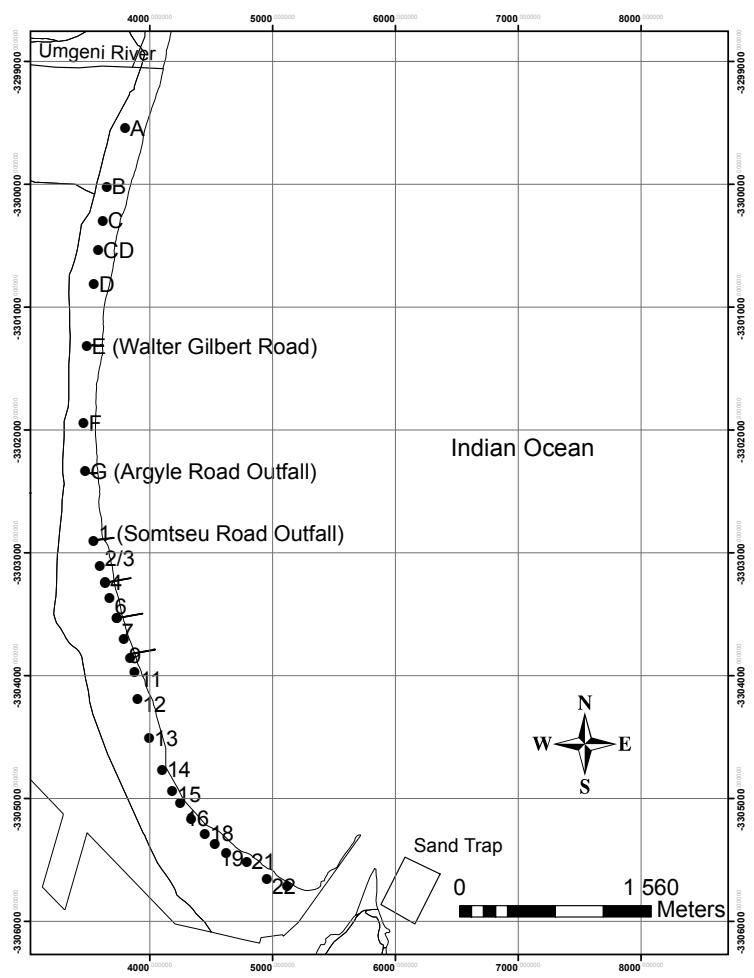

(c)

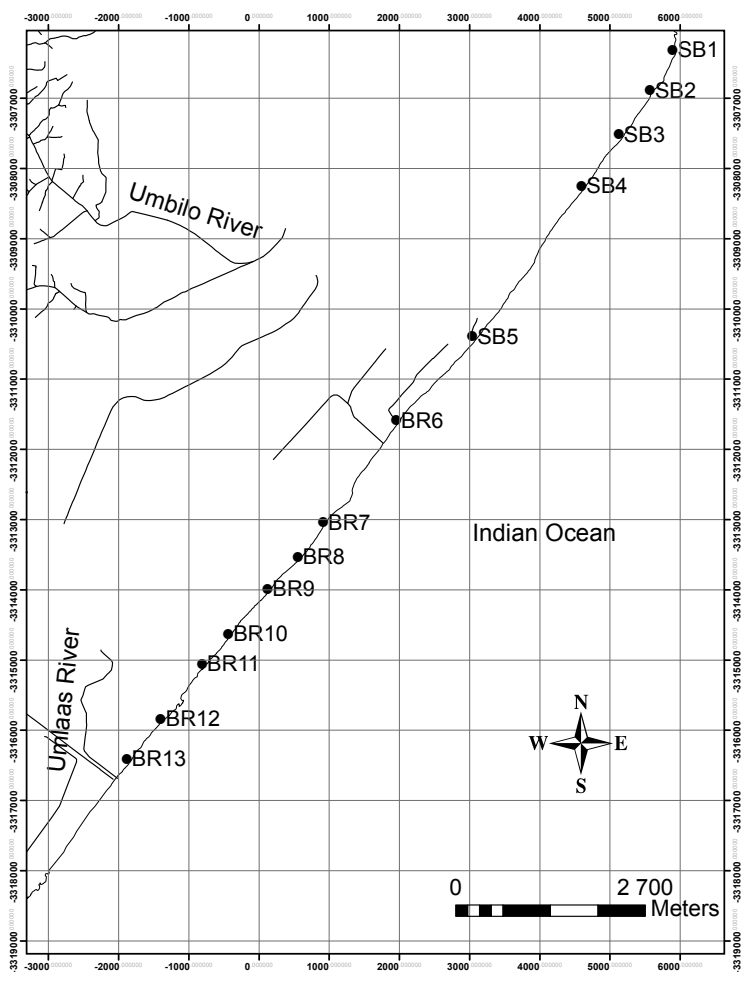

(b)

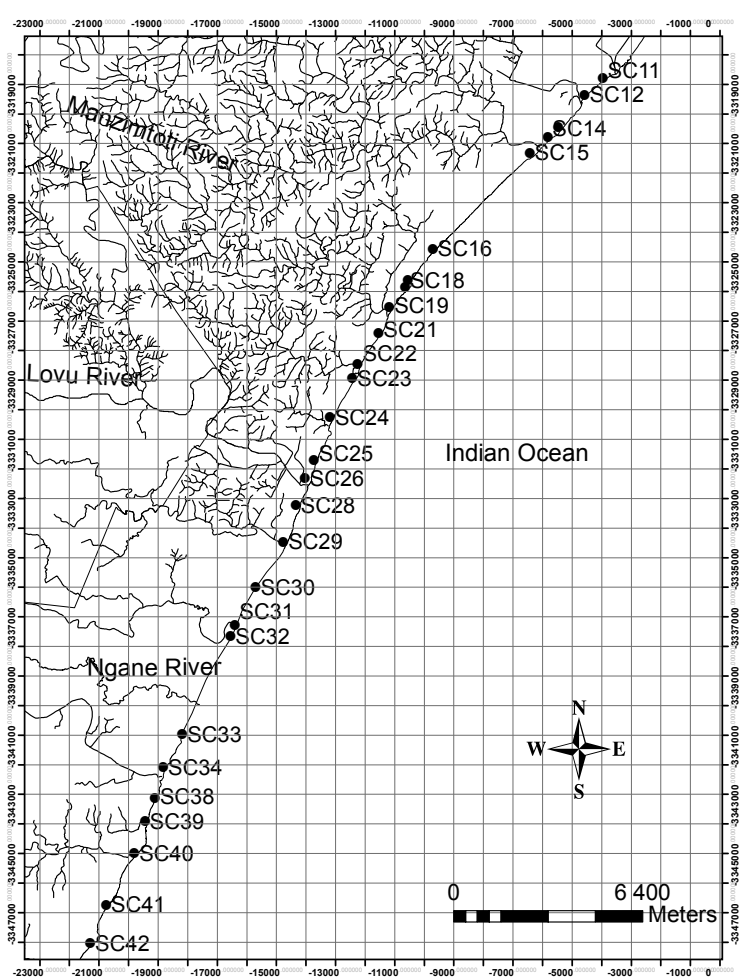

(d)

Fig. 2. Locations of beach profiles and rivers. Coordinate system: Lo 31 - WGS84. (a) From DN6 to DN13 of Durban North and from NC16 to NC35 of the North Coast (b) From SB1 to BR13 of the Durban Bluff (c) From A to 23 of the Durban Bight and the sand trap (d) From SC11 to SC42 of the South Coast. 


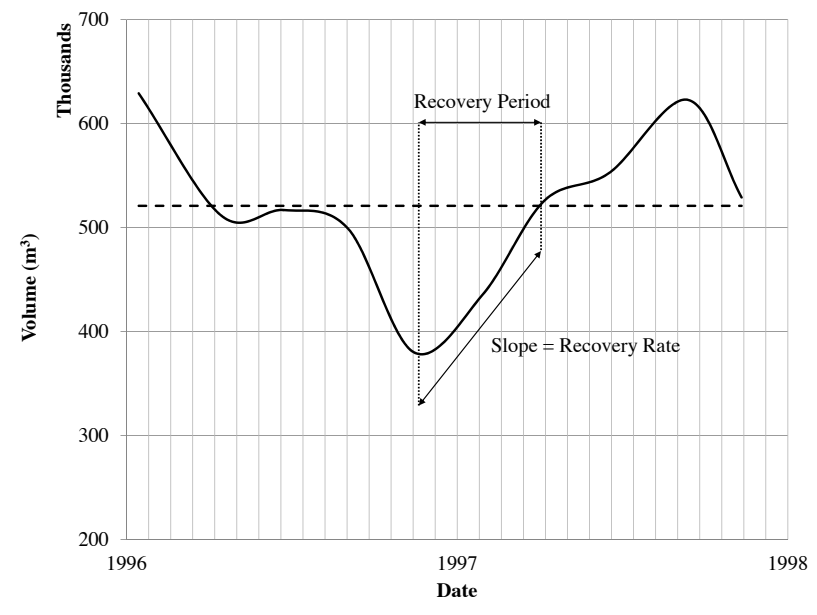

Fig. 3. Illustration of the recovery period and recovery rate of beach volume.

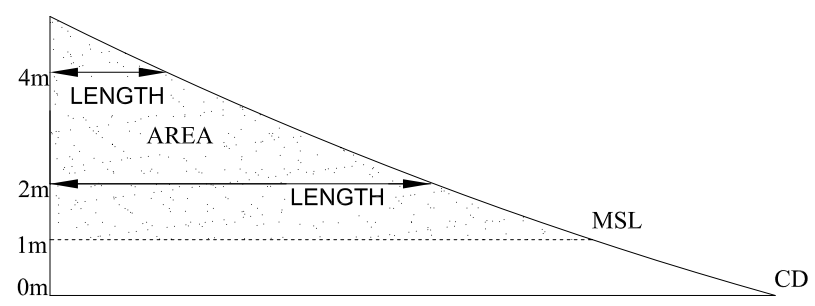

Fig. 4. Beach profile area (volume per metre) above $1 \mathrm{~m}$ chart datum (CD) and profile length at the $2 \mathrm{~m}$ and $4 \mathrm{~m} \mathrm{CD}$ contour.

Before the results are presented, it must be noted that the majority of Durban's beach profiles have been showing a long-term decreasing trend (Corbella, 2010). New erosion events are, therefore, recovering to lower average levels. One of the more extreme examples of this is shown in Fig. 5.

\subsection{Sediment balance}

The Durban Bight is affected by a sand bypass scheme (Fig. 2c). This provided the opportunity to identify erosion events by considering profile changes in conjunction with sand bypass volumes. The sediment balance is presented in Fig. 6 and shows the events of 1997, 2007 and 2003 (in descending order) to be the main erosion events. The 1997 event is also referred to as the 1998 event as this presented the lowest beach level following the 1997 event. Reference to the 2004 event similarly applies to the 2003 event. These events will be referred to as the major erosion events.

Figure 6 shows that 2005 was the only year that recorded a gain in volume. This is likely a result of the calm sea conditions and the fact that the beach volume was already at a low level. The percentage annual change in volume relative to the previous year was used to identify major erosion events.

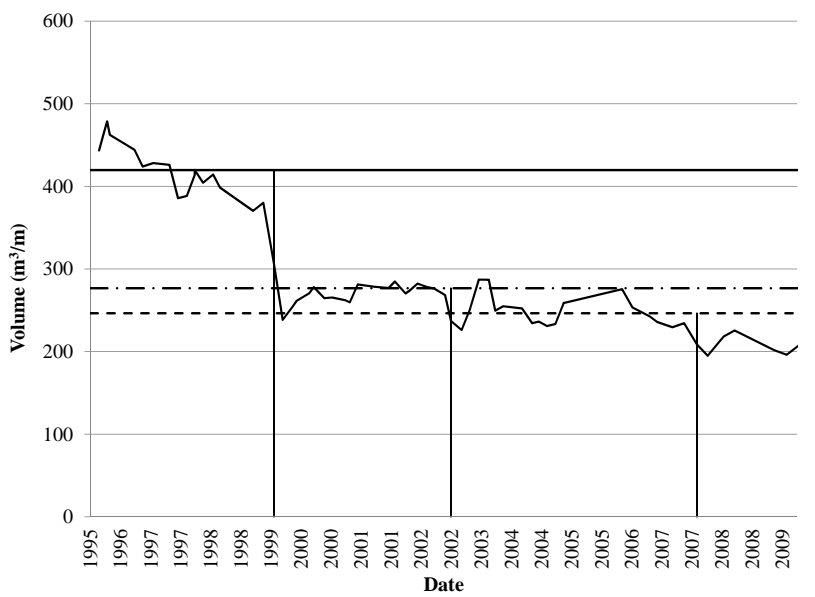

Fig. 5. The moving average volume of profile DN6 in Durban North (-). The average profile levels prior to the following erosion events are shown: 29 June 1999 by the solid line; 4 December 2002 by the dashed and dotted line; 12 September 2007 by the dashed line.

The year 2007 had the largest percentage loss corresponding to a volume loss of $35 \%$ of the previous year's volume. The year 1997 and 2003 accounted for a $33 \%$ loss. Note that pumped volumes from the sand bypass scheme are included in the sediment balance so the loss of sand shown could have occurred even if the profile volumes increased.

The major erosion events are typically attributable to individual severe storms, while smaller storms may also play a secondary role. Storms in this context are defined as episodic events with significant wave heights exceeding $3.5 \mathrm{~m}$ (Corbella and Stretch, 2011a). For example, the low level of sediment in 1998 was a result of a large storm in 1997 followed by several smaller storms in 1998 . The low of 2004 similarly resulted from the second largest storm on record in 2001 followed by a series of smaller storms. The low in 2007 was the result of the largest storm on record. The severity of erosion events may also be due to the coincidence of high waves with a $4.5 \mathrm{yr}$ extreme tidal cycle (Corbella and Stretch, 2011b). The extreme and infrequent events tend to have a general impact on all the profiles while smaller storms may have more localized impacts. The smaller storms also occur more frequently as part of the normal wave climate and are, therefore, not expected to individually affect the recovery rates in a significant way. The recovery rates that are being recorded in this paper may, therefore, be linked directly to the largest storms and extreme tidal cycles that were the main factors underpinning the major erosion events.

\subsection{Location grouped profile volumes}

Table 1 shows the location and event grouped profile volumes. The Durban Bight $(A-G)$ has a large variation in recovery period as its recovery is dependent on sand being 


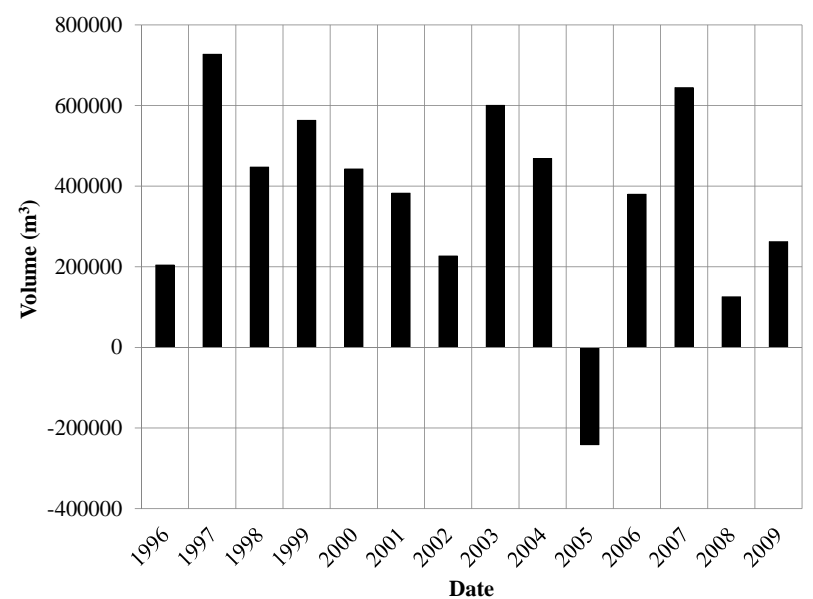

Fig. 6. Annual sediment losses for the Durban Bight (A - 23) accounting the sediment volumes contributed by the sand bypass scheme.

delivered via the sand bypass scheme which is limited to operate when sand is available from the sand trap and when conditions are appropriate for dredging. This recovery period is also dependent on the significance of the erosion event. The recovery rate of the Durban Bight is also expected to have a large standard deviation for similar reasons. The Durban Bight is obviously a unique portion of the coastline and it may not be appropriate to compare it with the remainder of the coast.

Excluding the Durban Bight, the average beach recovery period is $1.82 \mathrm{yr}$ at a rate of $61.33 \mathrm{~m}^{3} \mathrm{~m}^{-1} \mathrm{yr}^{-1}$ and the inclusive recovery period is $2.15 \mathrm{yr}$ at a rate of $80.34 \mathrm{~m}^{3} \mathrm{~m}^{-1} \mathrm{yr}^{-1}$. The results show that the different blocks recover differently from the same events. This difference in recoveries is the result of the different locations as well as that some blocks are more eroded than others from the same event. This suggests that erosion of a beach depends on the wave direction and orientation of the beach to the impending storm. It must be remembered that since the profiles show a decreasing trend, the 2007 event is generally recovering to a lower average profile level and, thus, may have a shorter recovery period relative to the other events.

It is interesting that the Bluff shows the shortest recovery time, but it has the slowest recovery rate. This would seem to imply that the Bluff beaches erode less from the events. This is only partly true, the reason they recover so quickly is a consequence of the majority of the beaches consisting of vegetated dunes (further discussed in Sect. 3.8) as well as the long-term erosion causing consequent recoveries at lower levels. This is visually depicted in Fig. 8 showing the preerosion event averages.

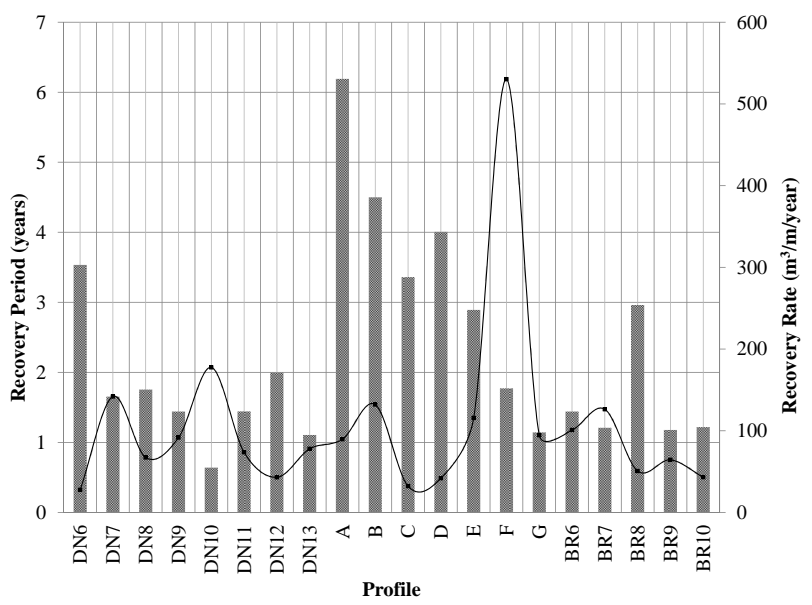

Fig. 7. Profile area recovery period shown by the bar graph and recovery rate shown by the line graph.

\subsection{Event grouped profile volumes}

It was evident from the location grouped recovery that recovery periods and rates are dependent on the profile location and the erosion event. Therefore, the profiles were divided into erosion events to establish how much the recovery periods and rates varied from the location groups.

The events with the largest recovery periods in descending order are 2007, 2004 and 1998 (see Table 2). The average recover period is $2 \mathrm{yr}$ and the rate is $97.3 \mathrm{~m}^{3} \mathrm{~m}^{-1} \mathrm{yr}^{-1}$. This is comparable with the averaged location grouped events.

\subsection{Individual profile volumes}

Finally, to explore the recovery dependence on location, individual profile recoveries were averaged across all erosion events. Figure 7 clearly demonstrates that the profiles are affected differently by storm events and also recover differently. Profiles $\mathrm{E}$ and $\mathrm{F}$ are adjacent to one another and are affected by the same events. Profile F recovers more than 4 times faster than profile $\mathrm{E}$. This is a result of $\mathrm{F}$ having an exceptionally fast recovery following the 2007 event which is a consequence of the location of low lying stormwater outfalls. Profile F is situated between two outfalls while $E$ is immediately up-drift of an outfall (Fig. 2c). This causes E to erode less than $\mathrm{F}$ during storm events, but also results in it recovering slower. F, on the other hand, erodes more, but consequently recovers faster as sediment is trapped between the outfalls. Other location factors influencing recovery are identified in Sect. 3.8 concerning recovery from the 2007 event.

The average recovery period is $2.27 \mathrm{yr}$ and the average rate is $104.2 \mathrm{~m}^{3} \mathrm{~m}^{-1} \mathrm{yr}^{-1}$. Considering the averages in their location groups provides a very similar result. Analysis of the volumes once again showed that each profile reacts differently to erosion events as well as recovers differently. 
Table 1. Location averaged profile recovery periods and rates for the Durban North, Bight and Bluff blocks and for the major erosion events.

\begin{tabular}{ccccccc}
\hline & \multicolumn{2}{c}{ Durban North (DN6 - DN13) } & \multicolumn{2}{c}{ Durban Bight (A - G) } & \multicolumn{2}{c}{ Durban Bluff (BR6 - BR10) } \\
\hline Event & Period (yr) & Rate $\left(\mathrm{m}^{3} \mathrm{~m}^{-1} \mathrm{yr}^{-1}\right)$ & Period (yr) & Rate $\left(\mathrm{m}^{3} \mathrm{~m}^{-1} \mathrm{yr}^{-1}\right)$ & Period (yr) & $\left.\mathrm{Rate}^{3} \mathrm{~m}^{3} \mathrm{~m}^{-1} \mathrm{yr}^{-1}\right)$ \\
\hline 1998 & 2.28 & 101 & 2.91 & 79.0 & 1.50 & 50.9 \\
2004 & 1.82 & 64.3 & 2.52 & 92.6 & 2.19 & 45.4 \\
2007 & 1.52 & 74.9 & 2.97 & 204 & 1.63 & 50.7 \\
\hline Std. Dev. & 0.38 & 27.8 & 0.25 & 74.8 & 0.36 & 3.12 \\
Mean & 1.87 & 73.7 & 2.80 & 118 & 1.77 & 49.0 \\
\hline
\end{tabular}

Table 2. Event grouped ensemble average recovery period and rate for the major erosion events.

\begin{tabular}{lcc}
\hline Event & Period $(\mathrm{yr})$ & Rate $\left(\mathrm{m}^{3} \mathrm{~m}^{-1} \mathrm{yr}^{-1}\right)$ \\
\hline 1998 & 1.89 & 90.0 \\
2004 & 2.13 & 57.9 \\
2007 & 2.11 & 118 \\
\hline Std. Dev. & 0.13 & 34.2 \\
Mean & 2.04 & 97.3 \\
\hline
\end{tabular}

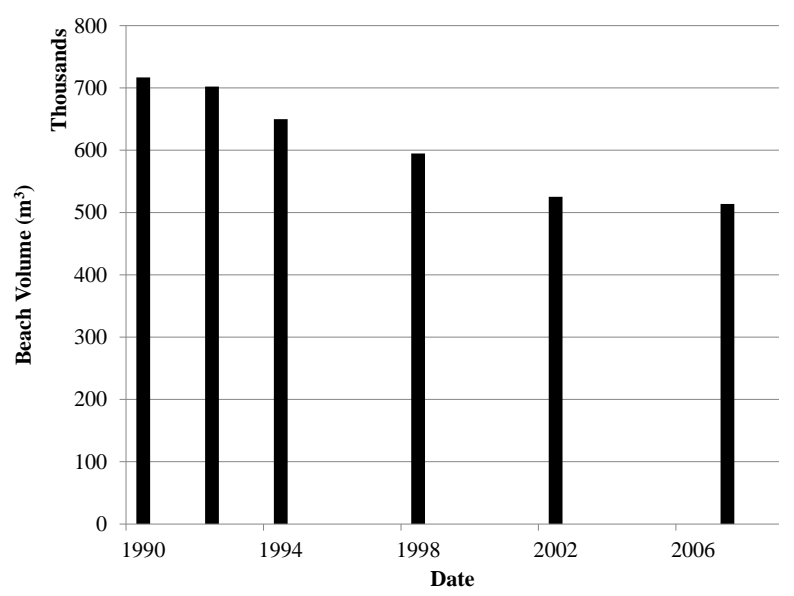

Fig. 8. The Bluff Block (BR6 - BR10) average pre-erosion event volumes.

\subsection{Profile length recovery}

The Durban Bight beach length data from 1973 to 2009 was put through a similar recovery analysis to that of the volumes. Once again the profiles 1 to 23 were not considered as they are thought to be too dependent on the sand bypass system. The 37-yr data set was significantly longer than the others and so the analysis was performed slightly differently to that of the volumes. Instead of creating a dynamic average that depends on the profiles pre-storm average, an average for all the profile lengths were created and this was used to establish a recovery period and rate.

The years 1980, 1986/1987, 1998 and 2007 were identified as significant erosion events. The recovery rates and periods were calculated and since they all made up the same location group they were averaged into events. The $2 \mathrm{~m}$ contour has an average recovery period of $1.3 \mathrm{yr}$ and a standard deviation of $0.24 \mathrm{yr}$. It also recovers an average of $39.4 \mathrm{~m} \mathrm{yr}^{-1}$. The standard deviations are relatively small for the $2 \mathrm{~m}$ contour with the 1979/1980 event being the only event responsible for a significantly longer recovery period. The $4 \mathrm{~m}$ contour length has a recovery period of $1.8 \mathrm{yr}$ and a large standard deviation of $0.95 \mathrm{yr}$. The recovery rate is $26.6 \mathrm{~m} \mathrm{yr}^{-1}$.

The difference in the recovery period between the $2 \mathrm{~m} \mathrm{CD}$ contours and the $4 \mathrm{~m} \mathrm{CD}$ contours is half a year. This demonstrates the effect of the beach morphology - although it may take only a year for the length to recover it may take much longer for the profile to recover to its pre-storm shape. This recovery process is what causes the perception of beach recovery. The beach is perceived to have recovered once it returns to its pre-storm length, but it is yet to recover to its full pre-storm cross-sectional area.

\subsection{Recovery comparison}

Analysing the average recoveries of the profiles in different groups highlighted the different dependencies in erosion and recovery. The various recovery periods and rates were then compared and averaged to establish an appropriate global recovery period and rate for the coastline. Table 3 gives a summary of the results.

The volumes take between 1.82 and $2.27 \mathrm{yr}$ to recover while the recovery rate is between 61.3 and $104 \mathrm{~m}^{3} \mathrm{~m}^{-1} \mathrm{yr}^{-1}$. The blocks and profiles erode and recover differently as a result of location. This results in the beaches recovering from storm events in 1.5 to $2.5 \mathrm{yr}$, depending on their location. These are consistent results since, by the end of 2009 , the beaches had made a full visual recovery from the 2007 event although they had not entirely recovered (recall 
that the decreasing trend means it has recovered to a lower average level). Since the waves are very similar along the $100 \mathrm{~km}$ of coastline (Corbella and Stretch, 2011a), it is safe to assume that erosion and the subsequent recovery is highly dependent on the location of the profile. In this regard the bathymetry, proximity of rivers (Fig.2) and orientation of the coast affects the sediment supply and the shoaling and refracting of waves.

\subsection{Unrecovered profiles}

Two factors responsible for long-term sediment loss, apart from sea level rise, are an overall decrease in sediment supply and the occurrence of multiple erosion events within the recovery period.

Reduced fluvial sediment supply to the coast in this region has been attributed to a combination of sediment mining and trapping of sediments in dams along rivers (CSIR, 2008). Large episodic flood events also contribute major sediment inputs when lower river reaches are eroded (CSIR, 2008). The last major regional flood event was in 1987 and the KwaZulu-Natal coastline may require another such event to counteract the chronic erosion.

If significant erosion events occur before a beach has recovered from previous events, the outcome will be a longterm decrease in sediment. Since there has not been any significant erosion events subsequent to the 2007 event, this factor cannot be considered in the analysis of that event.

Table 4 shows the profiles that do not recover before the next erosion event or do not recover at all. The 1996, 2004 and 2006 erosion events virtually made a full recovery prior to the subsequent events, with only $5 \%$ of the analysed profiles not recovering. The 1998 event was far more significant and over $6 \mathrm{yr} 45 \%$ of the analysed profiles were unable to recover. Only the Durban Bight, which is heavily stabilized and protected, recovered from the 1998 event before the 2004 event. The Durban North and Bluff beaches did not recover from the 1998 event before the 2007 event.

\subsection{Recovery from the 2007 event}

The recovery analysis demonstrated that the profiles recover differently depending on their location and the severity of the storm event. The recovery of all the profiles were analysed for the 2007 event to identify which physical features affect the recovery of beaches. Recovery periods were not calculated for profiles SC11 - SC44 and NC10 - NC35 because there was insufficient data to calculate a pre-erosion level. Fig. 9 presents the recovery rates and the recovery periods.

It can be seen from Fig. 9 that of the northern beach profiles DN6 and DN8 are amongst the profiles that take the longest time to recover. This is thought to be a result of this stretch of coast being exposed to direct wave attack. Profiles A to $\mathrm{D}$ take the longest to recover. This is a result of them being dependent on the sand bypass system and being the last beaches to receive the bypassed sediment subsequent to it being trapped by numerous outfalls and groynes along the way. In the Bluff area BR8 takes the longest time to recover. This appears to be a result of the rock outcrop in front of the profile that limits the deposition of sediment onto the beach profile. A stormwater outfall up-drift of the profile may also contribute to its slow recovery as a result of sediment being trapped.

Numerous profiles had extremely slow recovery rates. Slow recovery rates seem to be associated with open, unsheltered coastlines with rocky nearshore profiles. The main Umhlanga beach, NC3 - NC5, and NC36, the Bluff, BR6 $\mathrm{BR} 8$, and the majority of the south coast, SC14 - SC33 are examples of this type of coastline. The recovery rates of BR6 and BR8 were further hindered by a large stormwater outfall intercepting sediment up-drift of their location. Profile SC21 is located between two rocky headlands. It has a slow recovery rate as a result of the up-drift headland starving the profile of sand as well as possible wave focusing as they are refracted around the headland creating a rip current which further erodes the profile. Two profiles, SC33 and SC25, have continued to lose sediment after the event and, therefore, have negative recovery rates. In the case of SC33 this is thought to be due to the large rock outcrop just up-drift of that location. The continued losses at profile SC25 are due to northward migration of the estuary mouth at that location which has significantly eroded the profile (see Fig. $2 \mathrm{~d}$ and photographs provided in supplementary material). The high water table due to the perched back-barrier lagoon may also be contributing to on-going erosion.

Amongst the profiles with the shortest recovery periods were DN10, DN13, F and BR9. Profile DN13 has well established vegetated dunes while DN10 and BR9 have the same type of dune system as well as small outfalls that aid the trapping of sediment. A similar observation was made by Smith et al. (2010) who noted natural beaches recovered faster than urbanized coastlines. Profile F has an extremely fast recovery rate and, thus, a very short recovery period (only presented in Fig. 7 to allow for an appropriate scale in Fig. 9). Apart from the explanation given in Sect. 3.4, profile F was one of the few stretches of beach that had vegetated dune protection.

The profiles with the fastest recovery rates seem to be associated with beaches having densely vegetated dunes. Profiles NC38, NC7, DN10, F and BR9 are examples of this type of coast. Profile SB1 on the Bluff has a fast recovery as the storm is thought to have caused minimal erosion since the area consists of a rock revetment along the road and is enclosed by a large rock outcrop. As noted previously, profile BR9, DN10 and F are also affected by their proximity to stormwater outfalls. Profiles SC24 and SC26 are both down drift of river mouths and this sediment supply is thought to contribute to their rapid recovery.

The volumes took an average of $2.08 \mathrm{yr}$ to recover at a rate of $62.2 \mathrm{~m}^{3} \mathrm{~m}^{-1} \mathrm{yr}^{-1}$. This is comparable with the recoveries from other events. Tables 5 shows a comparison of the 
Table 3. Area recovery periods and recovery rates.

\begin{tabular}{ccc}
\hline Grouping Method & Average Recovery Period $(\mathrm{yr})$ & Average Recover Rate $\left(\mathrm{m}^{3} \mathrm{~m}^{-1} \mathrm{yr}^{-1}\right)$ \\
\hline Location \& event & 1.82 & 61.3 \\
Event & 2.04 & 97.3 \\
Profile & 2.27 & 104 \\
\hline Mean & 2.04 & 87.5 \\
\hline
\end{tabular}

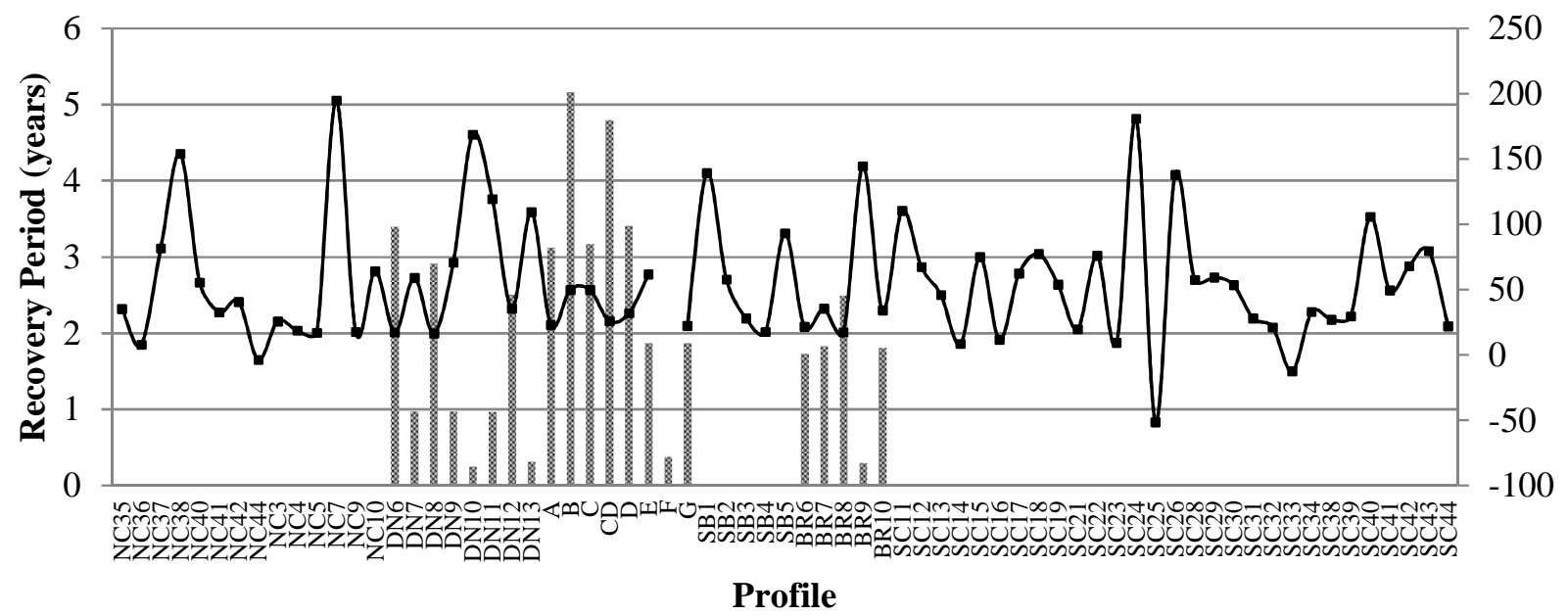

Fig. 9. Profile volume recovery period and recovery rate of the 2007 event shown by the bar graph and line graph, respectively.

Table 4. Unrecovered profiles from the corresponding erosion event.

\begin{tabular}{ccc}
\hline Event Year & Profile & \multicolumn{1}{c}{ Response } \\
\hline 1996 & A & Does not recover before next event \\
\hline 1998 & DN6 & Does not recover before next event \\
& DN7 & Does not recover before next event \\
& DN9 & Never recovers \\
& DN12 & Does not recover before next event \\
& DN13 & Does not recover before next event \\
& E & Does not recover before next event \\
& BR6 & Does not recover before next event \\
& BR7 & Does not recover before next event \\
& BR8 & Does not recover before next event \\
\hline 2004 & B & Does not recover before next event \\
\hline 2006 & DN9 & Does not recover before next event \\
\hline
\end{tabular}

volume recovery periods as well as the corresponding means. The average recovery time of the 2007 event was $2.08 \mathrm{yr}$.

It should be noted that $33 \%$ of the analysed profiles had still not recovered from the 2007 event by the end of 2010 and their recovery periods are projected from their recovery
Table 5. Average volume recovery periods.

\begin{tabular}{cc}
\hline Areas & Average Recovery Period (yr) \\
\hline Profile Areas & 2.11 \\
Location Areas & 2.05 \\
\hline Mean & 2.08 \\
\hline
\end{tabular}

rates. Although they have virtually recovered, they are still slightly below their pre-storm levels and in light of the longterm erosion trend many are not expected to ever recover.

Considering the location averaged areas, only the northern beaches do not fully recover which contribute to about a third of the recorded beach data. At the end of 2009, this was a noticeable feature of the KwaZulu-Natal coastline where there was visible evidence that the beaches had recovered, but still exhibited traces of the past event.

\section{Discussion}

The 2007 event was the largest event in $18 \mathrm{yr}$ and although it showed profile recovery times ranging from $0.5 \mathrm{yr}$ to potentially $6 \mathrm{yr}$ it still suggests an average recovery time of 
2 yr. This is similar to a global average calculated for all the major erosion events and is consistent with the findings of Choowong et al. (2009) and Liew et al. (2010) who found that the Thai coastline took two years to recover from the 2004 tsunami.

After erosion events, many of the profiles initially accrete very quickly creating the perception of recovery while as much as half may not yet have recovered. This is evident from the shorter recovery period associated with beach length. Morton et al. (1994) reported similar perceptions. The $2 \mathrm{~m} \mathrm{CD}$ contour profile length recovery period is shorter than the $4 \mathrm{~m} \mathrm{CD}$ contour length which in turn is shorter than the volume recovery. These recoveries imply that a full volumetric and geomorphic recovery of storm damaged beaches may require 4-5 yr as suggested by Morton et al. (1995).

It was found that open, rock sheltered coastlines (NC3 NC5 and BR8) take longer to recover than the sandy vegetated dune coastlines (NC38, NC7, DN10, F and BR9). Although a rock outcrop in the nearshore zone protects beaches from eroding under normal conditions, it also restricts accretion after an extreme event such as the 2007 event. Profiles up-drift of perpendicular beach structures (F) recovered the fastest while down-drift profiles (BR6) eroded further in the aftermath of the erosion events. Perpendicular beach structures include headlands (SC21) which can also accentuate erosion before and after a storm event by focusing waves. Liew et al. (2010) also observed variations in recoveries as a result of anthropogenic activities. Harris (2008) made similar observations with regards to intensely developed coastlines. The dunes of natural beaches aid recovery by providing a source of sand to replenish the eroded beach. During the storm event, the lower portion of the dune is stripped of vegetation. The destabilized dune then slowly collapses, contributing to the recovery. The remaining dune vegetation traps wind blown sediment and the dune recovers. These observations suggest that coastal managers should attempt to maintain natural coastlines with vegetated dunes.

River mouths and estuaries seem to influence the recovery of beaches (SC24 and SC26) by providing a replenishing supply of sediment. The influence of alluvial sediment is only evident in the later stage of recovery as the rapid initial recovery is from offshore sediments being returned to the shoreline. Even with the benefit of rivers, adjacent profiles are still considered as a management risk because the mouth can potentially migrate, especially after large storm events.

The profile recoveries demonstrate how both longshore and cross-shore transport processes contribute. The profiles that recover by both processes recover faster than those that only recover by one. This is evident from the profiles downdrift of stormwater outfalls and those sheltered by nearshore rock outcrops. The profiles down-drift of stormwater outfalls (BR6) can only recovery by cross-shore transport. The rock sheltered profiles (NC3 - NC5 and BR8) are not replenished by cross-shore transport and can only recover from longshore transport. CSIR (2008) estimated the longshore transport along the Bluff (SB1 - BR13) as $460000 \mathrm{~m}^{3} \mathrm{yr}^{-1}$, along the Bight $(\mathrm{A}-23)$ as $260000 \mathrm{~m}^{3} \mathrm{yr}^{-1}$ and north of the Umgeni River (Fig. 2a) as $315000 \mathrm{~m}^{3} \mathrm{yr}^{-1}$. The Bluff may recover faster than the northern beaches because it has a larger longshore sediment transport rate. However, this cannot explain why profiles $A-G$ recover fastest while having the smallest longshore transport, which suggests that crossshore processes contribute more to recovery in this instance.

Short (1999) presented various indices for the classification of beach types as reflective, intermediate or dissipative. Harris (2008) used these indices to characterise the KwaZulu-Natal beaches. Considering our division of the study area, the Durban Bight $(\mathrm{A}-\mathrm{G})$ beaches are mainly intermediate with dissipative beaches being restricted to the southern end of the Durban Bight $(1-23)$ while the southern (BR6 - BR10) and northern (DN6 - DN13) beaches are largely reflective. Reflective, intermediate and dissipative beaches are characterised by potentially low, medium and high cross-shore sediment transport, respectively (Short, 1999). These characterisations explain why the southern and northern beaches have a slow recovery rate and the intermediate central beaches have a relatively faster recovery rate. Unfortunately the dissipative beaches are the ones influenced by the sand bypass scheme and so do not represent a natural recovery. Based on the analysed data, it can be generalized that the profile areas above $1 \mathrm{~m} \mathrm{CD}$ of reflective beaches recover approximately $60 \mathrm{~m}^{3} \mathrm{~m}^{-1} \mathrm{yr}^{-1}$ and intermediate beaches recover approximately $120 \mathrm{~m}^{3} \mathrm{~m}^{-1} \mathrm{yr}^{-1}$ along the KwaZulu-Natal coast.

The dependance of recovery rates on the beach type can also be linked to sediment grain size. Based on two sediment samples taken in 2007 for all the profiles the average $D_{50}$ grain sizes were $0.88 \mathrm{~mm}$ on the northern beaches (N6NC44), $0.38 \mathrm{~mm}$ on the Durban Bight $(\mathrm{A}-\mathrm{G})$ and $0.43 \mathrm{~mm}$ on the southern beaches (SB1 - SC44). This implies that finer sediments are associated with faster recovery which can be attributed to the fact that they are more readily suspended and transported. Sediment grain sizes also affect the beach slope and, thus, determine whether the beach is reflective, intermediate or dissipative.

\section{Conclusions}

We have analysed $37 \mathrm{yr}$ of beach profile data. Profile lengths and volumes were calculated along with their pre-erosion average levels. These were then used to determine recovery rates and recovery periods. The recovery of storm damaged beaches has been shown to be dependent on the location of the beach and the severity of the storm event.

The beaches in the case study were found to take an average of two years to recover at a rate of about $90 \mathrm{~m}^{3} \mathrm{~m}^{-1} \mathrm{yr}^{-1}$. Long-term (chronic) sediment loss was identified in cases where storm damaged beaches have not recovered to preerosion levels. Beach profiles with vegetated dunes (NC38, 
NC7, DN10, F and BR9) recovered faster than urbanized beaches (G). Perpendicular beach structures have both positive (F) and negative (SC21) effects on beach recovery. Coastlines with rock outcrops in the surf zone (BR8) tend to recover slowly. These observations are consistent with simple physical arguments concerning the roles of longshore and cross-shore sediment transport processes, the effect of different sediment characteristics, and with changes in the overall supply of fluvial sediments to the coastal zone. We therefore expect that the results from our case study may be widely applicable.

Considering the observed differences in recovery rates, even for profiles that erode similarly, it is recommended that the recovery period of post storm profiles be included in risk analyses for coastal development. A fast recovering profile possesses less of a development risk than a slow recovering profile since it has a smaller probability of experiencing a subsequent erosion event before it has recovered from the initial event.

The results reported here may have important applications for the management of vulnerable coastlines.

\section{Supplementary material related to this article is available online at: http://www.nat-hazards-earth-syst-sci.net/12/11/2012/ nhess-12-11-2012-supplement.zip.}

Acknowledgements. The authors wish to thank the eThekwini Municipality for the use of the profile data.

Edited by: S. Tinti

Reviewed by: P. Nielsen and H.-J. Verhagen

\section{References}

Barnett, K. A.: The Management of Durban's Beaches: An Historical Perspective, Fifth International Conference of Coastal and Port Engineering in Developing Countries, COPEDEC V, Cape Town, 19-25 April 1999, 1999.

Callaghan, D. P., Nielsen, P., Short, A., and Ranasinghe, R.: Statistical simulation of wave climate and extreme beach erosion, Coast. Eng., 55, 375-390, 2009.

Callaghan, D. P., Ranasinghe, R., and Short, A.: Quantifying the storm erosion hazard for coastal planning, Coast. Eng., 56, 9093, 2009.

Choowong, M., Phantuwongraj, S., Charoentitirat, T., Chutakositkanon, V., Yumuang, S., and Charusiri, P.: Beach recovery after 2004 Indian Ocean tsunami from Phang-nga, Thailand, Geomorphology, 104, 134-142, 2009.

Cooper, J. A. G. and McKenna, J.: Social justice in coastal erosion management: The temporal and spatial dimensions, Geoforum, 39, 294-306, 2008.

Corbella, S.: A review of Durban's wave climate and storm induced changes, M.Sc, University of KwaZulu-Natal, Durban, 308 pp., 2010.
Corbella, S. and Stretch, D. D.: The wave climate on the east coast of South Africa, in review, J. S. Afr. Inst. Civ. Eng., 2011a.

Corbella, S. and Stretch, D. D.: Decadal trends in wave climate and beach erosion on the east coast of South Africa, in review, Nat. Haz. Earth Sys. Sci., 2011 b.

CSIR : Sand Supply from Rivers within the eThekwini Jurisdiction, implications for coastal sand budgets and resource economics, Report No. CSIR/NRE/ECO/ER/2008/0096/C, Stellenbosch, 2008.

De Michele, C., Salvadori, G., Passoni, G., and Vezzoli, R.: A multivariate model of sea storms using copulas, Coast. Eng., 54, 734-751, 2007.

Durgappa, R.: Coastal protection works, Seventh International Conference of Coastal and Port Engineering in Developing Countries, COPEDEC VII, Dubai, 1-15 March 2008, 97, 2008.

Forbes, D. L., Parkes, G. S., Manson, G. K., and Ketch, L. A.: Storms and shoreline retreat in the southern Gulf of St. Lawrence, Mar. Geol., 210, 169-204, 2004.

GESAMP: Anthropogenic Influences on Sediment Discharge to the Coastal Zone and Environmental Consequences, Joint Group of Experts on the Scientific Aspects of Marine Environmental Protection (GESAMP), GESAMP Reports and Studies No 52, UNESCO, 1994.

Gracia, V., Morón, D., Jiménez, J. A., Guillén, J., Palanques, A., and Sanchez-Arcilla, A.: Near-bottom transport seaward of the surf zone under storms: On the role of currents, wind and infragravity waves in microtidal environments, Proceedings of the 28th International Coastal Engineering Conference, Cardiff, 712 July 2002, 2, 2517-2527, 2002.

Harris, L. R.: The ecological implications of sea-level rise and storms for sandy beaches in KwaZulu-Natal, M.Sc, University of KwaZulu-Natal, Westville, 184 pp., 2008.

Houser, C., Hapke, C., and Hamilton, S.: Controls on coastal dune morphology, shoreline erosion and barrier island response to extreme storms, Geomorphology, 100, 223-240, 2008.

Kriebel, D. L. and Dean, R. G.: Convolution method for timedependent beach-profile response J. Waterway Port. C. Ocean Eng., 119 (2), 204-226, 1993.

Liew, S. C., Gupta, A., Wong, P. P., and Kwoh, L. K.: Recovery from a large tsunami mapped over time: The Aceh coast, Sumatra, Geomorphology, 114, 520-529, 2010.

Miller, J. K. and Dean, R. G.: A simple new shoreline change model, Coast. Eng., 51, 531-556, 2004.

Morton, R. A., Gibeaut, J. C., and Paine, J. G.: Meso-scale transfer of sand during and after storms: implications for prediction of shoreline movement, Mar. Geol., 126, 161-179, 1995.

Morton, R. A., Paine, J. G., and Gibeaut, J. C.: Stages and Durations of Post-Storm Beach Recovery, Southeastern Texas Coast, U.S.A., J. Coast. Res., 10, 4, 884-908, 1994.

Otter, H. S. and Capobianco, M.: Uncertainty in integrated coastal zone management, J. Coastal Conservation, 6, 23-32, 2000.

Shepard, F. P.: Longshore Bars and Longshore Troughs, Technical Memorandum 41, Beach Erosion Board, U.S. Army Corps of Engineers, Washington, DC., 1950

Schoonees, J. S.: Annual variation in the net longshore sediment transport rate, Coast. Eng., 40, 141-160, 2000.

Smith, A. M., Mather, A. A., Bundy, S. C., Cooper, J. A. G., Guastella, L. A., Ramsay, P. J., and Theron, A.: Contrasting styles of swell-driven coastal erosion: examples from 
KwaZulu-Natal, South Africa, Geol. Mag., 1-14, Cambridge University Press, 2010.

Short, A. D.: Handbook of Beach and Shoreface Morphodynamics, John Wiley \& Sons, Chichester, 379 pp., 1999.

van Gent, M. R. A., van Thiel de Vries, J. S. M., Coeveld, E. M., de Vroeg, J. H., and van de Graaff, J.: Large-scale dune erosion tests to study the influence of wave periods, Coast. Eng., 55, 10411051, 2008. van Rijn, L. C.: Prediction of dune erosion due to storms, Coast. Eng., 56, 441-457, 2009.

van Thiel de Vries, J. S. M., van Gent, M. R. A., Walstra, D. J. R., Reniers, A. J. H. M.: Analysis of dune erosion processes in largescale flume experiments, Coast. Eng., 55, 1028-1040, 2008. 